\title{
The Role of Management Sciences in Fostering Entrepreneurship Education in Nigerian Universities.
}

\author{
Onuoha Ijeoma Perpetua \\ Department of Business Education Ebonyi State College Of Education, Ikwo
}

\begin{abstract}
This study aims at suggesting the best Management Science practices for improving the effectiveness of entrepreneurial education programs in the Universities, based on their impact on expected attitudes of undergraduate students towards business start-up as a career choice. Particularly, the paper presents some results from a study carried out in two Nigerian Universities aimed at validating a structure of entrepreneurial education based on a double component of the circular role of management science teachings and extracurricular support, and to analyze their effects upon undergraduates' entrepreneurial self efficacy and outcomes as immediate antecedents of entrepreneurial intentions and behaviors. Statistical treatment of data was based on factorial, discriminate and regression analyses. Findings underlies the very limited involvement of Management Sciences of Nigerian Universities in entrepreneurial education as perceived by students, together with the existence of different effects of circular and extracurricular elements when fostering entrepreneurial careers among future graduates. Results show a relationship, though not very strong between Management Sciences and entrepreneurial capabilities. There was an examination of course structures and pedagogies in Management Sciences and entrepreneurial education, the paper then provides the results of University survey reflecting "current state" of Management Sciences and entrepreneurial education.
\end{abstract}

Key words: Entrepreneurship, Entrepreneurship Education, Fostering, Management Sciences, Nigerian Universities.

\section{Introduction}

In the context of the wide-ranging social and economic changes that have been occurring in industrialized countries over recent decades, new, small enterprise have become a key element in creating employment, wealth and social welfare in all modern, competitive economies. This is true to such an extent that encouragement for entrepreneurship is currently at the heart of a host of requirements and public standards in the countries of the EU, in an effort that has reached out to affect economic, social, employment and educational policies.

As a result of this political awareness, contemporary educational systems are seeing their missions expanded by the assignment of a further responsibility to provide a socio-economic boost, taking the form of the channeling of future generations of the working population towards entrepreneurial goals in accordance with the new needs of the productive sector through management sciences. Among all educational institutions, the universities' response to this aim is of particular relevance, since these are organizations with a high capacity to generate and disseminate specialized knowledge in the context of a social reality in which access to higher education is more and more general in developed countries.

Despite the fact that this political awareness has turned entrepreneurship education into a frequent topic in the specialized literature over the last three decades, (Vázquez, Naghiu, Gutiérrez and Placer, 2006), its systematic inclusion in University programs is still a pending matter in most African countries including Nigeria.

In this sense, most University academic programs in Nigeria, especially in Management Sciences have been centered so far on training wage-earner professionals, this prevalent approach becoming insufficient since unemployment, flexibility and over-qualification have become the more representative descriptors of young people's work insertion over the last decade in Nigeria and Europe in general.

For this reason, in the middle of the process of adaptation of the Nigerian university System through management sciences to the requirements of the new African Education Area (AHEA), it is important to reconsider whether the transformations undertaken, both in the university's aims and in the way in which these must be reached, will enable a better response to the social needs and expectations frequently assigned to university institutions. Therefore, since entrepreneurship can be seen as a promising option of work insertion and professional development of recent university graduates at the service of broader objectives of sustainable socio-economic welfare, some efforts are nowadays devoted to set up normative models for the articulation of coherent strategies to foster entrepreneurship initiatives through management sciences in contexts of higher education, based on the functions assigned to universities and the resources available to them. From this 
framework, the identification of the elements encompassed by entrepreneurship education and their potential effects on management science future graduates' career choices should be a priority concern.

Following the steps of this purpose, this paper is organized as follows. First, we review the guidelines marked by the European common policy with regard to the inclusion of entrepreneurship competences as part of the university academic mission and provide a global description of current entrepreneurship teaching and support in African and Nigerian institutions of higher education. Next, we propose a theoretical framework to analyze the effectiveness of entrepreneurship education programs based on the expected attitudes of students towards new venture creation as a management science career choice. According to that, we present an empirical study carried out in two Nigerian universities aimed to analyze the role of management science, at both curricular and extracurricular levels, in the development of entrepreneurial vocations among students. Finally, conclusions and implications of the study are discussed.

\section{Effects of Entrepreneurial Education in Management Sciences}

Shortages in University entrepreneurship education are congruent with the poor involvement of young University graduates in Management Science business initiatives. For example, in Spain, only $7.3 \%$ of new enterprises created in 2009 were initiated by an entrepreneur younger than 25 years old, and the average age of entrepreneurs were nearly 40 years old. What is more, despite the fact that $35.3 \%$ of Spanish entrepreneurs rely on higher education, they tend to start their business years after finishing the University degree (De la Vega, Corduras, Cruz, Justo and González, 2009). The same pattern of results has been observed in other European countries with a similar economic level (European Commission, 2007; Bosma and Levie, 2009).

In this context, justification of greater entrepreneurship education in Nigerian Universities is inherent in the potential outcomes derived from it in students. Hence, it should be a priority concern to develop practical models which help to identify the curricular mechanisms and institutional supports needed to articulate a new strategy in the University, aimed to facilitate the emergence of entrepreneurial interest and initiatives among students of Management Sciences.

On these lines, cognitive model of entrepreneurial intentions derived from the Theory of Planned Behavior (Ajzen, 1991) have been the approaches most often applied over the last few decades to the study of entrepreneurial behavior in University environments.

In simple terms, these models take it that business start-up derives from the formation of an entrepreneurial intention, which in turn is a direct consequence of individual attitudes towards the perceived desirability and feasibility of that behavior which convey the potential effects of other endogenous or exogenous variables such as education.

While it is true that some successes have been achieved by this line of study when explaining the effect of entrepreneurship education on undergraduates' entrepreneurial prospects (Corduras et al., 2008; Vázquez et al., 2009a, 2009b), several limitations have been recently noted with regard to its vague specification of the psychological constructs and educational variables used as predictors of entrepreneurial intents, together with other criticisms doubting the validity of the approach in predicting the entrepreneurial behavior of University students over the long term ( Chandlerm and Lyon, 2001).

From this framework, general career models adopted from Management Science literature may provide a better and more adjusted explanation of undergraduates' entrepreneurial behavior and its educational triggers, from the specific academic and professional reality experienced by students as they end their higher education. Based on Bandura's Social Cognitive Theory (1997), the model emphasizes the relevance of two psychological variables in explaining the establishment and development of career goals: self-efficacy and outcome expectations.Self-efficacy refers to "people's judgments of their capabilities to organize and execute courses of action required in attaining designated types of performances". That is, self-efficacy is an attribution of personal competence and control in a given situation. It is linked to initiating and persisting in behavior under uncertainty, to setting higher goals, and reducing threat-rigidity and learned helplessness (Bandura 1997).

In the context of careers, self-efficacy refers to the perceived personal capability to do a specific job or set of tasks. That is why the level of self-efficacy predicts career choice and occupational interests (Bandura, 1997), including the entrepreneurial option. People avoid careers and environments which they believe exceed their capacities, and undertake careers for which they consider themselves capable. From this view, entrepreneurial self-efficacy has been defined as the person's belief in their own abilities to perform the various skill requirements necessary to pursue a new venture opportunity (Chen et al., 1998). Some research studies have demonstrated the predictive power of entrepreneurial self-efficacy beliefs on entrepreneurial intentions and behaviors (De Noble et al., 1999; Zhao et al., 2005; Vázquez et al., 2009a, 2010).

Whereas self-efficacy beliefs are concerned with one's response capabilities (i.e., "Can I do this?"), outcome expectations involve the imagined consequences of performing particular behaviors (i.e., "If I do this, what will happen?"). Several theories place a heavy emphasis on the relation of expected outcomes and action. 
For example, Vroom's (1964) model view choice behavior as being largely dependent upon the subjective probability that certain acts will produce particular outcomes, together with the value one places on those outcomes.

Based on these arguments, Social Cognitive Theory suggests that "people act on their judgments of what they can do, as well as on their beliefs about the likely effects of various actions" (Bandura, 1997, p. 231). In this respect, Bandura (1997) distinguished between several classes of outcome expectations with potential to affect career behavior, such as the anticipation of physical (economic incomes), social (approval), and selfevaluative (self-satisfaction) outcomes.

Several studies carried out with samples of university students show a positive relationship between anticipation of positive consequences and entrepreneurial intentions and behaviors (Douglas and Shepherd, 2002; Carter et al., 2003; Cassar, 2007; Edelman et al., 2010; Vázquez et al., 2009a, 2010).

Furthermore, some previous works assume that both entrepreneurial self-efficacy and outcome expectations can be easily enacted by educational situations (Vázquez et al., 2010). In fact, previous research suggest that participation in specific entrepreneurship education programs derive in perceptions of competence for business start-up (Zhao et al., 2005; Vázquez et al., 2009a, 2010), favorable attitudes towards selfemployment and related entrepreneurship preferences and intentions (Vesper and Gartner, 2006; Vázquez et al., 2009a, 2010).

While this line of study backs up the positive effects of entrepreneurship education, identification of specific elements affecting undergraduates' entrepreneurial behavior has received less attention in the literature. In this sense, educational constructs most often used as independent variables in previous studies correspond to generalities in terms of academic level, area or performance, and subjective perceptions regarding the availability or participation in poorly defined learning situations. At the same time, samples have often consisted of participants in specific and voluntary courses or programs, thus leading to a frequent self-selective bias linked to individuals with certain predisposition towards entrepreneurship (Kickul and Marlino, 2007).Infact, previous empirical evidence does not seem to offer a clear stamp of what Educational components influence on what individual dimensions and with which effects.

To fulfill this gap in the literature, the principal aim of this paper is twofold. First, we intend to validate a structure of entrepreneurship education through management sciences based on a double curricular and extracurricular component of teaching entrepreneurship contents (including specific knowledge, abilities and attitudes) and institutional support to business start-up. Second, we seek to analyze the effect of both components on undergraduates' entrepreneurial self-efficacy and outcome expectations as immediate antecedents of entrepreneurialchoices and intentions. Based on these purposes, the next section describes a self reporting study carried out with a sample of undergraduates in Nigeria.

\section{The Role of Management Sciences in Entrepreneurial Education}

Management science is concerned with developing and applying models and concepts that help to illuminate management issues and solve managerial problems. The models used can often be represented mathematically, but sometimes computer-based, visual or verbal representations are used. The range of problems and issues to which management science has contributed insights and solutions is vast in Entrepreneurships. It includes scheduling airlines, both planes and crew, deciding appropriate place to site new facilities such as warehouse or factory, managing the flow of water from reservoirs, identifying possible future development paths for parts of the telecommunications industry, establishing the information needs and appropriate systems to supply them within the health service and identifying and understanding the strategies adopted by companies for their information systems. Management science applies advanced analytical methods to business problems to help mangers of entrepreneurship make better decisions. Therefore, management science and entrepreneurial education represents quantitative approach to solving problems in business. Management science helps in the use of statistical and mathematical methods to make business decisions. Simply, it is the study of statistical methods such as linear programming and simulation in order to analyze entrepreneurial ventures.

\section{Research Methodology and Results}

In order to make the generalization of results possible to different institutional contexts, the study sample consisted of undergraduate students at two Nigerian Universities with different tradition, size and international prestige: the University of Nigeria and Ebonyi State University.

Established in 1960 by Dr. Nnamdi Azikiwe, an African legend who was also Nigeria's first President, and with more than 20,000 students, the University of Nigeria is one of the Universities of reference in Nigeria,occupying favorable positions in many international classifications based on research quality criteria, formative capacity and demand, availability of physical and human resources, international presence etc.On its 
part, the Ebonyi State University belongs to the majority group of Nigerian Universities of less age and moderate dimensions, being composed of nearly 13,000 students after 13 years of history.

Despite the discrepancies described, both Universities fit the requirements of thestudy, since they are engaged in several initiatives aimed to foster entrepreneurship via management sciences among students, in the form of business chairs and specific institutional foundations and programs of management sciences. Thus, according to the paper objectives, the exposure of students in the study to some degree of entrepreneurship education through management sciences was ensured.Once justified by the choice of the two universities mentioned, data collection wasperformed from February to June 2012. Participants were registered from the finalyear of former first and second cycle that are being phased out in Nigeria, in order to provide evidence of the state of the matter in students with adequate previous University experience and derive recommendations of use in determining the structure of the new Bachelor-level degrees suited to the AHEA ${ }^{1}$ The total sample comprised a total of 800 University students (400 from each University), ensuring a criterion of representativeness of $95 \%$ (being $\mathrm{e}= \pm 5 \% ; p=q=0.50$ ).

1 The new Bachelor-level degrees suited to the AHEA began to be implemented in some Nigerian Universities during the 2009-10 and 2010-11 academic years, completing 47.8\% of the process to be ended in the course of the 2011-12 academic year (Ministry of Education,2009).Participants were selected through a procedure of stratified sampling, in accordance with the real distribution of students by field of study in each university. Based on this procedure, $53.1 \%$ of respondents indicated a main academic background on Social Sciences and Law, $14.6 \%$ on Technical Subjects, $12.3 \%$ on Health Sciences, $11.3 \%$ on Experimental Sciences, and $8.8 \%$ on Humanities. Among the total of participants, 530 were females (66.3\%) and 270 males (33.8\%), aged 18 to 48 years old, the meanAge being $23.16(S D=3.14)$.

\section{Measures}

In gathering data for the study, we developed a self-reporting questionnaire following a careful procedure to ensure an adequate content validity of scales. Specifically, we used a deductive approach based on the operational definition of the theoretical constructs arising from an in-depth review of the specialist literature on the topic and other similar tools for measurement, intended to identify specific indicators upon which to build up the scales. Similarly, the final version of the questionnaire was the product of refining the items included based of the opinions of three experts in the field about the suitability of the proposed indicators for measuring the variables of interest.Data collection was based on a procedure of collective voluntary self-administrationof the final questionnaire to groups of students. This was done in the context oftimetabled university classes, randomly selected for each knowledge area, afterobtaining approval from the academic member of staff responsible in all cases and in the presence of a researcher trained for this end.The questionnaire administered comprised various scales for measuring the variablesincluded in the model: entrepreneurship education in terms of both curricular teaching and extracurricular institutional support, and the potential results of entrepreneurial self-efficacy and outcome expectations.Measurement of entrepreneurship curricular teaching was based on academic experiences reported by students in learning ten conceptual contents ("contribution of enterprises to socioeconomic development", "the process of identification and assessment of business ideas", "steps in business start-up" etc.), ten skills ("leadership and management", "planning and organization", "risk-taking and assessment" etc.), and eight attitudes ("initiative", "proactiveness", "creativity") specified according to the "European Framework on Key Competences for Lifelong Learning" (Recommendation 2006/962/EC of the European Parliament and of the Council). Respondents were asked to rate the perceived importance assigned to each content in their respective academic programs, on a eleven-point Likert-type scale from 0 ("not important at all") to 10 ("very important").Entrepreneurship extracurricular support was assessed through nine items aboutthe perceived home university implication in actions aimed to provide resources andsupport to potential entrepreneurial initiatives of students ("campaigns to raise the entrepreneurial spirit", "business start-up counseling", "and financial resources" etc.).

For each item, participants had to answer on a Liker-type scale ranging from 0 ("notimplicated at all") to 10 ("very implicated").To assess entrepreneurial self-efficacy we asked students about their perceptionsregarding the competence to execute ten typical entrepreneurship activities, forexample, "to identify a business opportunity in the market", "to gather the resources needed to pursue a business opportunity", and "to manage a new enterprise". For each entrepreneurial activity, responses were ranged on a Likert-type scale from 0 ("completely incapable") to 10 ("perfectly able").Outcome expectations were measured by using a scale of 14 items referred topotential rewards derived from becoming an entrepreneur, such as "economic incomes", "social approval" and "self-satisfaction". Respondents were asked to report their degree of accordance with the possibility to obtain each outcome on a Likert-type scale from 0 ('strongly disagree') to 10 ('strongly agree').According to sample description purposes, in a final section of the questionnairerespondents were invited to indicate some socio-demographic information concerningtheir gender, age, home university and academic discipline. 


\section{Construct Validity}

Once data was collected and processed, we used principal components factor analysis with the SPSS 15.0 program to test the construct validity of the variables included in the model.Prior to performing factor analysis, the suitability of data was assessed. Inspection of the correlation matrix revealed the presence of many coefficients of .30 and above. Also, the Kaiser-Meyer-Ohlin value was .94, exceeding the recommended value of .60 and the Barlett's Test of Sphericity (Bartlett, 1954) reached statistical significance, supporting the factorability of the correlation matrix. Principal components analysis revealed the presence of eight factors with eigenvalues exceeding 1, explaining a $66.86 \%$ of the total variance. Nevertheless, using Catell's scree test, it was decided to retain only seven components for further investigation. To aid in the interpretation of the seven components identified, Varimax rotation was performed. The rotated solution presented in Tables 1 and 2 revealed, firstly, the multidimensionality of the entrepreneurship curricular teaching scale, according to the three dimensions of knowledge, skills and attitudes adopted in the "European Framework on Key Competences for Lifelong Learning" (Recommendation 2006/962/EC of the European Parliament and of the Council). In this sense, every item had a loading above .40 in its respective construct, explaining the $9.72 \%, 6.63 \%$, and $10.68 \%$ of the variance. Otherwise, entrepreneurship institutional support and entrepreneurial self-efficacy were confirmed as one-dimensional constructs of nine and ten indicators respectively, explaining $11.08 \%$ and $11.33 \%$ of the total variance.

Finally, the outcome expectations construct was better explained as a dimensional variable of two components which explained $9.42 \%$ and $6.23 \%$ of the variance. The first component, called intrinsic outcome expectations was composed of eight items concerned to the potential rewards of entrepreneurial initiative in terms of one' sown interest and self-satisfaction inherent to that activity. Secondly, a component of extrinsic outcome expectations was identified, composed of six items about the positive consequences derived from business start-up as an instrumental behavior, such as economic incomes or social approval. In total, the seven components identified explained $65.10 \%$ of the variance.

Moreover, all the scales retained were associated to Cronbach's $\alpha$ values of reliability over the recommended 70 (Bartlett, 1954)

Table 1: Factor Analysis Results for Educational Variables

\begin{tabular}{|c|c|c|c|c|}
\hline \multicolumn{3}{|l|}{ Entrepreneurship Curricular Teaching } & \multicolumn{2}{|c|}{$\begin{array}{ll}\text { Management } & \text { Science } \\
\text { Extracurricular } & \\
\text { Support } & \end{array}$} \\
\hline Knowledge & & Skills & Attitudes & \\
\hline Economic entrepreneurship Contribution & 756 & & & \\
\hline Entrepreneurs' work functions & 712 & & & \\
\hline Identification of business opportunities & 685 & & & \\
\hline Business structure and functioning & 674 & & & \\
\hline Business start-up as a career choice & 673 & & & \\
\hline Business models by academic area & 654 & & & \\
\hline Steps to start a business & 573 & & & \\
\hline Planning and organization abilities & 615 & 615 & & \\
\hline Management abilities & 605 & 605 & & \\
\hline Analysis and assessment abilities & 507 & 507 & & \\
\hline Self-knowledge abilities & 505 & 505 & & \\
\hline Communication abilities & 492 & 492 & & \\
\hline Risk-taking and assessment & 455 & 455 & & \\
\hline Autonomous work abilities & 445 & 445 & & \\
\hline Proactiveness & 763 & & 763 & \\
\hline Responsibility & 758 & & 758 & \\
\hline Goal self-direction & 755 & & 755 & \\
\hline Creativity & 725 & & 725 & \\
\hline Initiative & 722 & & 722 & \\
\hline Innovativeness & 721 & & 721 & \\
\hline Independence & 720 & & 720 & \\
\hline Change flexibility & 719 & & & \\
\hline Entrepreneurship counseling & & & & 848 \\
\hline Business plan assistance & & & & 829 \\
\hline
\end{tabular}


The Role of Management Sciences in Fostering Entrepreneurship Education in Nigerian Universities.

\begin{tabular}{|l|l|l|l|l|}
\hline Access to resources for business start-up & & & & 829 \\
\hline Information about business creation & & & & 817 \\
\hline Entrepreneurship training courses & & & & 972 \\
\hline Motivation and encouragement Actions & & & & 772 \\
\hline Mentorship and monitoring & & & & 745 \\
\hline Receptivity to alumni's interest & & & & 687 \\
\hline Raising the entrepreneurial spirit & & & & 629 \\
\hline Percentage of variance explained & $\mathbf{9 . 7 2 \%}$ & $\mathbf{6 . 6 3 \%}$ & $\mathbf{1 0 . 6 8 \%}$ & $\mathbf{1 1 . 0 8 \%}$ \\
\hline Cronbach's $\square$ reliability & $\mathbf{9 2}$ & $\mathbf{9 1}$ & $\mathbf{9 2}$ & $\mathbf{9 5}$ \\
\hline
\end{tabular}

Sources: Adapted from the European Framework on Key Competences for Life Long Learning (Recommendation 20061962 \EC of the European Parliament and of the Council.

Table 2: Factor Analysis Results for Behavioral Variables

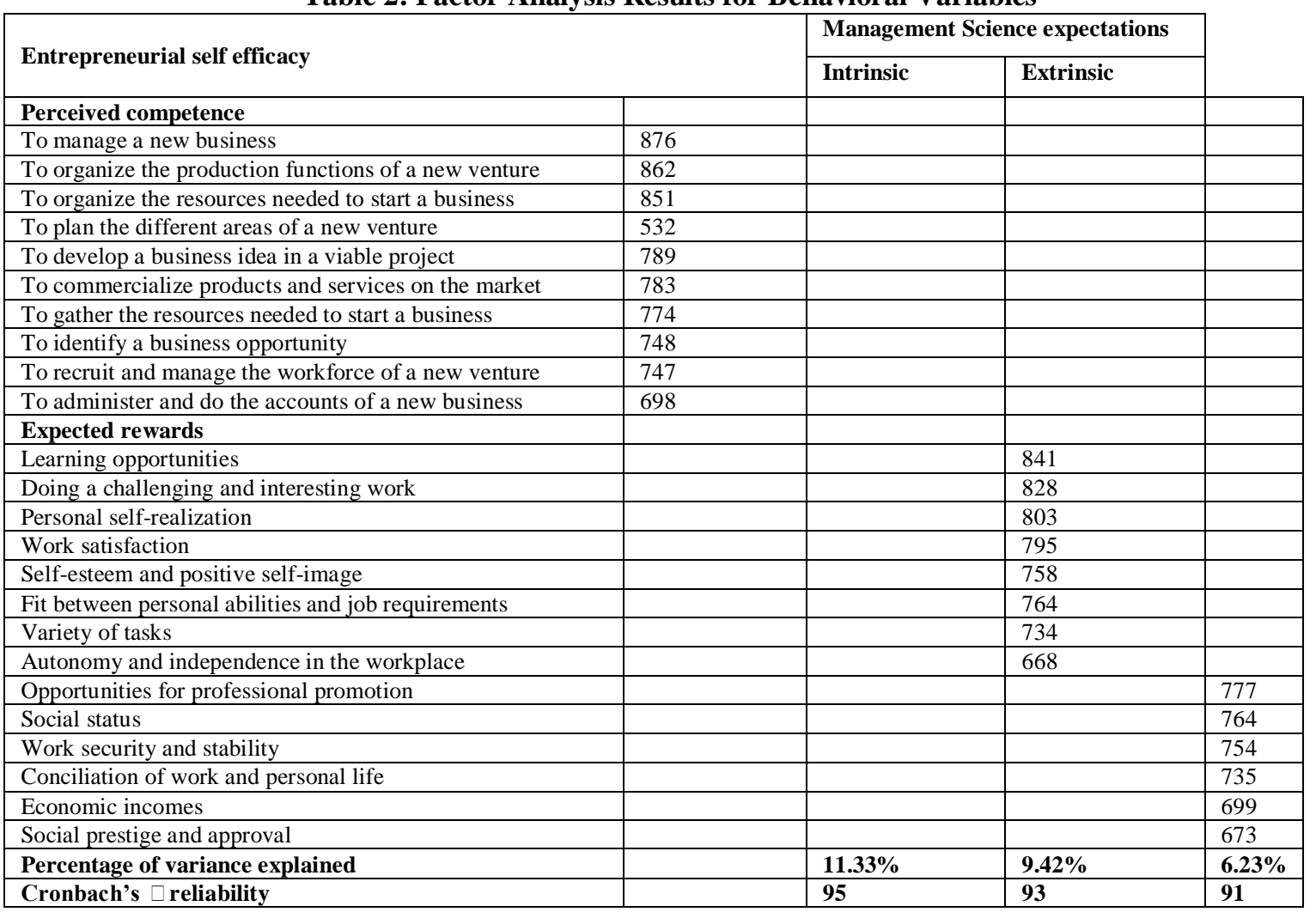

Sources: Adapted from the European Framework on Key Competences for Life Long Learning (Recommendation 20061962 $\mathrm{VEC}$ of the European Parliament and of the Council.

Table 3 presents the Means, Standard Deviations and Correlation Coefficients among the factors identified. In descriptive terms, entrepreneurship education efforts were poorly valued by students, with average scores under the intermediate value of 5 on the 0 to 10 scale in the four constructs of curricular teaching of entrepreneurial knowledge $(M=3.41)$, skills $(M=4.07)$ and attitudes $(M=4.56)$, and institutional support to business start-up $(M=2.56)$

Otherwise, participants showed moderate perceptions of competence to become self-employed, with a mean score of 5.12 in the entrepreneurial self-efficacy scale. At the same time, potential outcomes linked to entrepreneurial careers were favorablyassessed by students at both intrinsic $(M=7.82)$ and extrinsic levels $(M=$ 6.83).Correlations displayed in the table point to many positive significant relations among variables, these being higher among educational variables on one hand (with $r$ values between .48 and .71 ) and behavioral dimensions on the other (with $r$ values between .27 and .63), thus supporting the convergent and discriminant validity ofthe scales. 
Table 3: Regression Analyses

\begin{tabular}{|c|c|c|c|c|c|c|c|c|}
\hline & Mean & SD & & & & & & \\
\hline & Niean & SW & 1 & 2 & 3 & 4 & 5 & $\mathbf{0}$ \\
\hline 1.Knowledge & 3.41 & 1.94 & & & & & & \\
\hline 2. Skills & 4.07 & 1.96 & $66^{* * *}$ & & & & & \\
\hline 3.Attitudes & 4.56 & 2.07 & $48 * *$ & $71 * *$ & & & & \\
\hline 4. Support & 2.56 & 1.95 & $.61 * *$ & $53 * *$ & $.48^{* *}$ & & & \\
\hline 5.Self-efficacy & 5.12 & 2.11 & $29 * *$ & $.20 * *$ & $.13 * *$ & $24 * *$ & & \\
\hline 6.Intrinsic OE & 7.82 & 1.64 & $.10 * *$ & $.10 * *$ & $.09 * *$ & -.01 & $.27 * *$ & \\
\hline 7.Extrinsic OE & 6.83 & 2.06 & $07 *$ & $.12 * *$ & $13 * *$ & .06 & $32 * *$ & $.63 * *$ \\
\hline
\end{tabular}

$* p<.05 ; * * p<.01$.

To test the effect of management sciences in entrepreneurship curricular and extracurricular education onthe behavioral results of entrepreneurial self-efficacy and outcome expectations andanalyze the predictive validity of the measures employed, we ran three regressionmodels as shown in Table 5.Model 1 tested the effect of perceived learning of entrepreneurship knowledge,skills and attitudes and institutional support on entrepreneurial self-efficacy. It was found that, collectively, the educational variables explained a significant proportion of the variance in self-efficacy $(F=19.81, \mathrm{R} 2=.09, p<.001)$, whereas only perceived learning of entrepreneurial knowledge $(\beta=.23, p<.001)$ and entrepreneurshipextracurricular support $(\beta=.11, p<.05)$ caused a significant effect on that dependent variable. Curricular teaching of entrepreneurship skills and attitudes, however, were not significantly related to perceived self-efficacy.Model 2 was used to analyze the relationship between the four educationaldimensions previously mentioned and intrinsic outcome expectations. The overallequation was significant $(F=3.53, \mathrm{R} 2=.02, p<.005)$, and so was the coefficientfor perceived education of entrepreneurship skills $(\beta=.14, p<.05)$. In this case, neither perceived learning of entrepreneurship knowledge and attitudes, nor perceived extracurricular support affected the intrinsic rewards expected from self-employment.Finally, model 3 tested the effect of curricular and extracurricular entrepreneurship education on the third dependent variable of extrinsic outcome expectations. Again, the overall effect was significant $(F=3.79, \mathrm{R} 2=.02, p<.005)$, but only the coefficient of perceived curricular teaching of entrepreneurial attitudes reached statistical significance $(\beta=.10, p<.05)$, whereas the reminded educational variables did not affect the extrinsic outcomes anticipated from new venture creation.

Table 4: Results of Regressions

\begin{tabular}{|c|c|c|c|c|c|c|}
\hline & \multicolumn{2}{|c|}{ Model 1 (self-efficacy) } & \multicolumn{2}{|c|}{ Model 2 (Intrinsic OE) } & \multicolumn{2}{|c|}{ Model 3 (Extrinsic OE) } \\
\hline & $\square$ coefficient & t-statistic & $\square$ coefficient & t-statistic & $\square$ coefficient & t-statistic \\
\hline Knowledge & $23 * * *$ & 4.58 & -.07 & -1.32 & -.01 & -0.26 \\
\hline Skills & 0.4 & 0.67 & $.14 *$ & 2.30 & .07 & 1.14 \\
\hline Attitudes & -.06 & -1.13 & .05 & 1.05 & $.10^{*}$ & 1.82 \\
\hline Support & $.11^{*}$ & 2.37 & -.06 &.-1.29 & -.01 & -017 \\
\hline $\mathbf{F}$ & \multicolumn{2}{|l|}{$19.81 * *$} & \multicolumn{2}{|l|}{$3.53 * *$} & \multicolumn{2}{|l|}{$3.79 * *$} \\
\hline $\mathbf{R}^{2}$ & \multicolumn{2}{|l|}{.09} & \multicolumn{2}{|l|}{.02} & \multicolumn{2}{|l|}{.02} \\
\hline Adj. $\mathbf{R}^{2}$ & \multicolumn{2}{|l|}{.08} & \multicolumn{2}{|l|}{.01} & \multicolumn{2}{|l|}{.01} \\
\hline
\end{tabular}

$* p<.05 ; * * p<.01 ; * * * p<.001$.

\section{Conclusion}

Entrepreneurial activities act as one of the main driving forces for economic and social development around the world. African governments have become increasingly aware of that. In the last decade, a great amount of political measures have been suggested to include entrepreneurship education as part of the academic curricula in higher education institutions. However, most high level programs seem to be much more centered on training wage-earner managers or technicians, than offering qualified and responsible entrepreneurs and enterprises to society.In this context, the identification of the elements encompassed by entrepreneurship education and management sciences and their potential effects on future graduates' career choices should bea priority concern. To this end, this paper has presented some results from a studycarried out in two Nigerian Universities aimed to validate a structure of entrepreneurship education and management sciences based on a double curricular and extracurricular component of teaching entrepreneurship contents (including specific knowledge, abilities and attitudes) andinstitutional support to business start-up, and to analyze their effect on undergraduates'entrepreneurial self-efficacy and outcome expectations as immediate antecedents ofentrepreneurial choices and intentions.In general, the results obtained made it clear that there is very limited involvementof NigerianUniversities in entrepreneurship education as perceived by students of management sciences,together with the existence of three main different effects of curricular teaching andextracurricular support when fostering entrepreneurial careers among students.First, undergraduates' entrepreneurial selfefficacy seems to be mainly enactedby learning experiences of entrepreneurship knowledge and support to businessstart-up at the University. In applied terms, this findings backs up the premise thatunderstanding of 
what entrepreneurship is and of how to become an entrepreneur,together with raising support and accompaniment services lead students to feelconfident on the feasibility of choosing an entrepreneurial career.Second, training of entrepreneurial skills such as project management, representationand negotiation, autonomous work, self-knowledge, and risk taking has a positiveeffect on the anticipation of intrinsic outcomes in entrepreneurial pursuits. Hence, the larger the future graduates' acquired entrepreneurial abilities, the higher theirexpectations to obtain self-evaluative rewards by means of entrepreneurship and management sciences.And third, curricular teaching of entrepreneurial attitudes only influenced extrinsic outcome expectations, thus pointing to the conclusion that development of personal characteristics to behave entrepreneurially has a positive impact on the external rewards expected in business start-up. That is to say, attitudinal training leads students to become more aware of the real instrumental benefits derived from entrepreneurial careers.In sum, this pattern of results reaffirms the need to reinforce the joint potential of Universities' curricular and extracurricular attempts in the design of specific proceduresapplicable to the setting up of an integrated strategy for entrepreneurship education in Management Science courses.At a curricular level, the climate of change currently in vogue offers an excellent opportunity to work on the design of teaching programs, thus, meeting the requirements to encourage entrepreneurship. To serve this curriculum planning effort, and by way of suggestions for good practices, the empirical model arising fromthe work described above sets the adoption of a skill-based teaching model that willplace the knowledge, abilities and attitudes necessary for an adequate developmentof entrepreneurship at the very heart of any educational intervention.

With the support of these prescriptions, the adoption of student-centered strategiesfor teaching, fundamentally by means of a diversification from theoretical methodsof training into experimental and cooperative forms of learning, must be seen as the most effective approach for the purposes of entrepreneurship education in theUniversities.

Similarly, in view of the effects attributable to extracurricular programsencouraging entrepreneurship upon perceived self-efficacy for the creation ofenterprises, it is also possible to argue in favor of increasing the amount of institutionalresources devoted to this purpose. This would attempt to favor access by undergraduates to resources appropriate to their needs, converting entrepreneurial initiative into a viable occupational alternative that potentially could be put into practice immediately at the end of their studies. The results obtained in the study must be interpreted in the light of certain methodological limitations, which leave the door open for further work in this field.In this respect, it should be noted that the majority of scales used for measuring the variables in the model were drawn up ad hoc for the purposes of this investigation. Hence, they will require future validation to check their usefulness for the purposesassigned to them in this work. At the same time, further longitudinal analyses are needed to give an account of the development of initial processes of selection of entrepreneurial careers into the tangible form of new successful enterprises in the Market-place. This would be by means of following up the entrepreneurial sequenceas it develops over time among the same group of students.Furthermore, it would be appropriate to expand the focus of the investigation adoptedhere through the inclusion of other endogenous or exogenous factors with a potential to cause direct influences or moderate many of the relationships found between variables. Such a line of work would constitute a more decisive advance towardsthe identification of the personal, behavioral and environmental processes likely tobe affected by higher education in attempts to encourage student entrepreneurialinitiatives.Finally, while the fact that the empirical study was carried out in two differentNigerian universities demonstrates that the conclusions drawn from it are sufficientlysolid, further studies are required to allow generalization of the results to other Nigerianor African institutions. It would even be appropriate to consider other models oftertiary education with the aim of gaining greater precision in the identification of thefactors in curriculum planning or the institutional environment itself that determine the level of effectiveness attained in encouraging entrepreneurial initiative in the young.

\section{References}

[1]. Ajzen, I. (1991), 'The Theory of Planned Behavior', Organizational Behavior and Human Decision Processes, Vol. 50 (2), pp. 179-211.

[2]. Bandura, A. (1997), Self-efficacy: The Exercise of Control, New York: W.H. Freeman.

[3]. Barlett, M.S., (1954) 'A Note on the Multiplying Factors for Various Chi Square Approximations', Journal of the Royal Statistical Society, Vol. 16, pp. 296-298.

[4]. Bosma, N. and Levee, J. (2009), Global Entrepreneurship Monitor, Executive Report, GERA and Babson College, MA, Babson Park. 271.

[5]. Corduras, A., Urbano, D., Rojas, A. and Martinez, S. (2008), 'The Relationship between University Support to Entrepreneurship with Entrepreneurial Activity in Spain: A Gem Data Based Analysis', International Advances in Economic Research, Vol.14, pp. $395-406$.

[6]. Carter, N.M., Gartner, W.B., Shaver, K.J. and Gatewood, E.J., 'The Career Reasons of Nascent Entrepreneurs', 2003, Journal of Business Venturing, Vol. 18, (1), pp. 13-39.

[7]. Cassar, G. (2007), 'Money, Money, Money? A Longitudinal Investigation of Entrepreneur Career Reasons, Growth Preferences and Achieved Growth', Entrepreneurship and Regional Development, Vol. 19 (1), pp. 89-107.

[8]. Chandlem, G.N. and Lyon, D.W. (2001) 'Issues of Research Design and Construct Measurement in Entrepreneurship Research: The Past Decade', Entrepreneurship Theory and Practice, Vol. 25, no. 4, pp. 101-113. 
[9]. Chen, C.C., Greene, P.G. and Crick, A. (1998), 'Does Entrepreneurial Self-Efficacy Distinguish Entrepreneurs from Managers, Journal of Business Venturing, Vol. 13, pp. 295-316.

[10]. De Noble, A., Jung, D. and Ehrlich, S. (1999), 'Entrepreneurial Self-Efficacy: The Development of a Measure and its Relationship to Entrepreneurial Action', in Reynolds, P.D.,

[11]. Douglas, E.J. and Shepherd, D.A., (2002) 'Self-Employment as a Career Choice: Attitudes, Entrepreneurial Intentions, and Utility Maximization', Entrepreneurship Theory and Practice, Vol. 26 (3) pp. 81-90.

[12]. Edelman, L.F., Brush, C.G., Manolova, T.S. and Greene, P.G. (2010), 'Start-up Motivations and Growth Intentions of Minority Nascent Entrepreneurs', Journal of Small Business Management, Vol. 48(2), pp. 174-196.

[13]. European Parliament Council Decision 1639/2006/EC, (2006). Establishing a Competitiveness and Innovation Framework Program (2007 to 2013), Official Journal of the European Union, pp. 15-40.

[14]. "European Framework on Key Competences for Lifelong Learning", (2006). Recommendation 2006/962/EC of the European Parliament and of the Council. Official Journal of the European Communities, pp. 84-91.

[15]. Kickul, J. and Marlino, D. (2007), 'Gender, Entrepreneurial Self-Efficacy, and Entrepreneurial Career Intentions: Implications for Entrepreneurship Education', Entrepreneurship Theory and Practice, Vol. 31, (3), pp. 387-406.

[16]. Ministry of Education, (2009). Implementation of the New Bachelor-Level Degrees Suited to the AHEA in some Nigerian Universities During the 2009-10 and 2010-11 academic years, Completing 47.8\% of the Process in 2011-12 Academic Year.

[17]. Vázquez, J.L., Naghiu, A., Gutiérrez, P. and Placer, J.L.(2006), 'University and Entrepreneurship: Some Results from the Spanish Legio Experience 2002-06', Buletinul USAMVCN, Seria Agricultura, Vol. 63(1-2), pp. 1-6.

[18]. Vroom, V.H. (1964), Work and Motivation, New York: Wiley, 34. Wilson.

[19]. Zhao, H., Seibert, C. and Hills, C., 'The Mediating Role of Self-Efficacy in the Development of Entrepreneurial Intentions', 2005, Journal of Applied Psychology, vol. 90, (6) pp.1265-1272. 